\title{
TASK-TECHNOLOGY FIT AND PERSON-JOB FIT: A BEAUTY CONTEST TO IMPROVE THE SUCCESS OF INFORMATION SYSTEMS ${ }^{1}$
}

\author{
Woro Dwi Suryani \& Sumiyana \\ Universitas Gadjah Mada \\ (worosuryani@gmail.com)
}

\begin{abstract}
This study raises the issue that information system success could be enhanced by complementing other factors. This study investigates the success of information systems by inducing ${ }^{2}$ the task-technology fit (TTF) and person-job fit (PJF) into the DeLone and McLean model. This study aims to examine, among the two induced factors, which one is able to explain and improve the success of the information systems implementation.

The results of this study indicate that the TTF explains the models' goodness of fit better than that of the PJF when induced into the modified DeLone and McLean model. This study implies this in terms of both theory and practice. Theoretically, this research presents an alternative research model that can be used to investigate the success of information systems by considering the aspect of the users' cognitive suitability (the cognitive fit theory). Furthermore, practically, this study suggests the importance of focusing on users' skills and competencies and, subsequently, management should do so. Additionally, the TTF recommends a simple proposition that it could be attached immediately into the individuals' skills and competencies. However, the PJF needs to be deeply embedded in the job's qualifications and recruitment policies.
\end{abstract}

Keywords: DeLone and McLean Model, inducement, task-technology fit, person-job fit

\section{INTRODUCTION}

This study focuses on the development of a new research model to assess the success of information systems implementation, both voluntary and mandatory. In 1992, DeLone and McLean published a model for information system success. This model was updated by DeLone and McLean in 2003, and hereinafter we refer to the (modified) DeLone and McLean model. Iivari (2005) conducted research using the modified DeLone and McLean model on the implementation of information systems in Oulu City Council, Finland. Our study develops his research further by inducing new dimensions, namely the task-technology fit and person-job fit.

Khayun et al. (2012) disclosed some phenomena and reasons for information systems applications in the public sector. Khayun et al. (2012) also found some problems in the online tax system in Thailand. Most of the industries' users there preferred to go directly to the tax office rather than use the online tax service (e-excise). So, they investigated the e-government application related to the e-excise service and found that the e-government implementation was voluntary.

\footnotetext{
${ }^{1}$ This article had been presented in National Accounting Symposium, $17^{\text {th }}$ in The University of Mataram, Lombok, Indonesia. We got a good paper nomination from this symposium. We are grateful to all critics, recommendations and suggestions from this symposium. This article initially is the master thesis of the first author with the second author as the promoter. Comments and suggestions can be sent directly to: sumiyana@ugm.ac.id, and woro_dwi90@yahoo.com.

2 The authors choose the word 'induce' based on Sumiyana, et al. (2010). Sumiyana, et al. (2010) defines that 'induce' means adding something into a model that can provide additional or more extensive influence. Oxford (2003) defines 'induce' as significant effect of proposition, an addition of into the form of constructs, or anything that can give an effect.
} 
In addition, DeLone and McLean (2008) signify that, at the organizational level, all the dimensions do not contribute to their success model.

Goldfinch (2007) finds that the failure of information system implementation occurs more commonly in the public sector. The amount of money spent to build the system had no effect on the level of the information system's success. Lakshmi (1991) also states that the development of information systems in the public sector is still far behind the private sector. This is attributed to the differences in the characteristics between the two sectors, such as culture, allocation of funds, and policy making.

This study assumes that, first, the users will benefit from the use of information systems according to their expertise and the work they perform, and also whether the users have the skills required to use the technology. Second, the users should have the agility to use the information system, so that they will able to adapt to the new information system. Third, the users will experience satisfaction if the system is able to provide them with what they need to complete their job as expected.

This study contributes to the management of the information systems development and implementation. This can be explained as follows. The development and implementation of information systems requires individuals to put more emphasis on the person-job fit (PJF) (Dihshaw and Strong, 1999) rather than the task-technology fit (TTF) (Klopping and McKinney, 2004). It is based on the cognitive fit theory (Vessey, 1991) which describes the correspondence between one's work and his/her expertise. The recent system users no longer have problems regarding the technology, but the success of the system relies on the skills and competencies of the people required for the job.

This section presents the introduction, and then the rest of our discussions are as follows. The next section presents the theoretical basis and hypotheses development for the information system's success, the cognitive fit theory, person-job fit (PJF), and task-technology fit (TTF) in the perspective of the modified DeLone and McLean model. Then, we further analyze and compare the two inducement models. The last section is the study's conclusions.

\section{LITERATURE REVIEW}

Various studies related to the implementation of information systems in the public sector have been carried out by previous investigators, such as Goldfinch (2007), Khayun, et al. (2012), DeLone and McLean (2008), Thompson, et al. (2009), and Iivari (2005). Goldfinch (2007) conducted research on the skepticism and failures of information system's implementation in the public sector. The research reviewed available studies related to the failure of information system's development in the public sector. The study explained that the success rate of information system's implementation in the public sector only reached $18 \%$. The research was based on a survey carried out in the United States of America.

Goldfinch (2007) showed that the important factors causing the failure of the system's development were enthusiasm, supervision, the principal-agent relationship, and information reliability. Enthusiasm consists of idolization, technophilism, lomanism, and managerial faddism. Idolization is reflected by the public sector employees who usually prefer a new information technology system, and see that as a great career benefit. Technophilism is a belief in the myth that information technology is able to solve practical problems. Lomanism is described as being organizations that are persuaded by the sellers of the latest information technology that the information technology will satisfy the needs of the organization. Managerial faddism shows the tendency of consultants to appoint managers who are believed to have the ability to resolve or prevent problems and to create profits.

Khayun et al. (2012) also conduct research on the application of information systems in the public sector. Their research subject was the application of e-government at the tax office in Thailand, namely e-excise. The e-excise system is an integrated online tax payment method. The nature of this system is voluntary. The users of this e-excise system are the owners of industries in Thailand. This study tried to assess the infor- 
mation systems success using the DeLone and McLean model. They used the Delphi Technique to investigate the critical success factors in eexcise implementation. The results of the study showed that many industries had no motivation to use this system and still preferred to pay taxes manually, because of the lack of trust by the users toward the e-government websites.

DeLone and McLean (2008) also reviewed the success of information systems implementation. They reviewed 180 articles related to the validation of the DeLone and McLean model from 1992 to 2007. Their study aimed to determine what was already known and what was still needed to investigate the success of system implementation at the organizational level. It employed qualitative methods by categorizing the DeLone and Mclean model into organizational and individual levels, identifying all the relationships in the latest DeLone and Mclean model, and examining specifically each construct within the DeLone and McLean model. The results of the review show that, at the organizational level, only a few of the dimensions in their model could identify their relationship.

Thompson, et al. (2009) conducted research related to the assessment of the success of egovernment implementation. They used the modified DeLone and McLean model and examined the role of trust in the success of information system's implementation. The model was tested by a survey of 214 e-government users in Singapore. The nature of the system is voluntary. They used post-hoc analysis to examine the influence of the nature of usage (active and passive) on the relationships among the success dimensions. The results showed that trust has a dominant influence on e-government usage, but it is trust in the government and not in the technology.

Iivari (2005) tested the DeLone and McLean model using a mandatory information system. In his research, he focused more on the success of an individual information system application using the modified DeLone and McLean model. The research, furthermore, attempted to test the effect of information systems on individual performance, measured by perceived usefulness.
Iivari (2005) also assumed that the perceived usefulness essentially affects the productivity of decision-making. However, the perceived usefulness is not directly focused on performance. Iivari (2005) conducted this research on the implementation of information systems in the public sector in Finland, namely the Oulu City Council.

\section{DeLone and McLean Model}

In 1992, the DeLone and McLean published a model of information system success. Their research referred to the previous research by Shannon and Weaver (1949) and Mason (1978). The subject of the referred research was communication. Shannon and Weaver (1949) divided communication into 3 levels, i.e. the technical level, semantic level, and effectiveness level. Based on the 3 levels, DeLone and McLean classify the success of systems into technical success, semantic success, and effectiveness success. Technical success is measured by the system's quality. The quality of the information becomes the measure of the semantic success, while the effectiveness success is measured by the users' satisfaction, individual impact, and organizational impact (Mason, 1978).

Several studies attempt to validate the DeLone and McLean model. Seddon and Kiew (1994) who conducted a survey of 104 users of a university accounting system found a significant relationship between the system's quality with the users' satisfaction and individual impact, the information quality with the users' satisfaction and individual impact, and the users' satisfaction with the individual impact. Additionally, Rai et al. (2002) tested the validity of the DeLone and McLean model by surveying 274 students. The results showed that some indicators of the model are significant and some are insignificant. However, the coefficient of the dimensions in the DeLone and McLean model is generally significant.

The success dimensions of the modified DeLone and McLean model have been updated. This modification is based on the criticism expressed by Seddon (1997). Seddon (1997) 
considered that the DeLone and McLean model was confusing. In addition, Seddon (1997) selected dimensions incorrectly because he combined the process and the success causality explanations into a single model. Grover et al. (1996) suggested that the DeLone and McLean model should be updated based on the organizational effectiveness theory. Grover (1996) also used this theory to establish the constructs of the information systems effectiveness. In the end, DeLone and McLean (2003) add the service quality and net benefits as the new dimensions of information system success.

\section{Cognitive Fit Theory}

The cognitive fit theory (Vessey, 1991) signified the fit between the task and the presentation format of information. This theory is used to solve the problems faced by users of the system in completing their work. The cognitive fit theory tries to explain how to solve the problems of presentation related to the tables, graphs, and matrices so as to distinguish the tasks that will have an impact on the efficiency of the task completion time. Vessey (1991) argued that technology can be used to reduce the task or job complexity if there is a good fit between the task and the presentation of the information or problem. A good fit results in the improvement of users' performance and the system will be more effective and efficient to use. To solve the problem, someone will create a mental representation based on the information he/she receives. The mental representation illustrates how someone looks at the problem with his/her limited memory (Gentner and Stevens, 1983). When there is a mismatch between the task and the presentation of information, the users should make extra cognitive efforts to convert the information into a suitable format to accomplish their task. This can slightly improve the users' performance.

The concept of cognitive fit has been used to explain the users' behavior and to predict the speed and accuracy of decision making and problem solving. For example, users will be able to easily and efficiently find some information when the format is in accordance with the user's task, so that they can get more relevant informa- tion (Kamis, et al., 2008). On the other hand, the information obtained by the users may support their performance in completing the task. In the application of mandatory systems such as Gadjah Mada's Accounting and Finance Information Systems (GM-AFIS) which is selected as this research's subject, the cognitive fit also needs to be owned by each user. Users who interact directly with the system must have the cognitive ability and have to understand the format of the information presented by the system. When the users' cognitive abilities and the presentation format of the information are unsuitable, the users might encounter problems in completing their task. This will impact on the performance of the users themselves.

The failure of system applications often occurs when the needs of users' cognitive abilities do not meet the information presented by the system. The users who have difficulties in using the system will indirectly make more effort to comprehend the information presented by the system so that their tasks can be completed and their performance is increased. Based on the cognitive fit theory, the authors assume that the level of complexity faced by the users in performing the GM-AFIS can be minimized by synchronizing the information presented by the system with the users' cognitive abilities. The users will be required to improve their cognitive abilities when facing information that is difficult to understand when completing their tasks. The more frequently they improve their cognitive abilities, the more easily they will resolve similar problems. The cognitive fit will impact on the efficiency of the task completion time to improve the users' performance.

\section{Task-Technology Fit (TTF)}

Goodhue and Thompson (1995) developed the task-technology fit. They suggested that it is the usability degree of the information technology that helps individuals to accomplish their tasks. It adapts among task's needs, individual capability, and technology function. It is designed to evaluate all of the information technology systems that are possessed by an organization compared to an individual application. 
Goodhue (1995) also stated that evaluation of users by using the TTF will be determined by their jobs, the individuals themselves, and the information system's characteristics.

Goodhue (1995) used 8 dimensions to measure the TTF. They are the data quality, local capability of data, authorization to access data, data compatibility, training and ease of use, production timeliness, system reliability, and IS relationship with users. The TTF contains 2 components, i.e. tasks that should be conducted by the user and the technologies that are used to accomplish users' tasks. Goodhue (1995) subsequently explains that the TTF has an ideal profile formed from a group. It has dependent tasks that are internally consistent with the use of the technological elements. Then, it could improve individuals' performance through task enforcement.

\section{Person-Job Fit (PJF)}

Thomson and Higgins (1995) defined the PJF as a measure of how far individuals trust that using information technology could enhance their job performance. The PJF concept is similar to the perceived usefulness proposed by Davis (1989) in the TAM model. The PJF focuses on the users' fit amongst knowledge, skill, and capability with their job (Carless, 2005). The PJF will be achieved when the job design and requirement meet with individual needs (Edward, 1991; Kristof-Brown et al., 1996; 2000).

Cable and DeRue (2002) conducted the PJF's measurement to assess it by identifying the needs-supplies fit (occupational characteristics and job attributes) and demands-abilities fit (per- formance requirements). The needs-supplies fit is the individuals' need of the balance between the job's occupational characteristics and the supplies (abilities) that he or she provide to fill the job's position. The demands-abilities fit are the balance between job's formation need and the individual capability to fill the job's formation.

\section{Hypothesis Development}

This research is the extension and development of Iivari's (2005) study. Iivari (2005) validated the modified DeLone and McLean (1992) model. He examined the application of the accounting and financial information system run by the City Council of Oulu, Finland and the system's mandatory nature. Presented below (Figure 1) is the research model used by Iivari (2005).

This study uses the modified DeLone and McLean model. The model adds the service quality and net benefits factors. It also combines the existing dimensions of the DeLone and McLean model with additional variables such as the perceived ease of use, person-job fit, and task-technology fit. The perceived ease of use determines the individuals' psychological behavior in using the information system. The tasktechnology fit serves as an indicator to determine the suitability of the characteristics of the task that is being run by the Directorate of Finance Gadjah Mada University. The characteristics of the task-technology fit are subsequently used to support the application of GM-AFIS.

Not all the dimensions of the DeLone and McLean model are used in this study. The dimensions which are not used in this study,

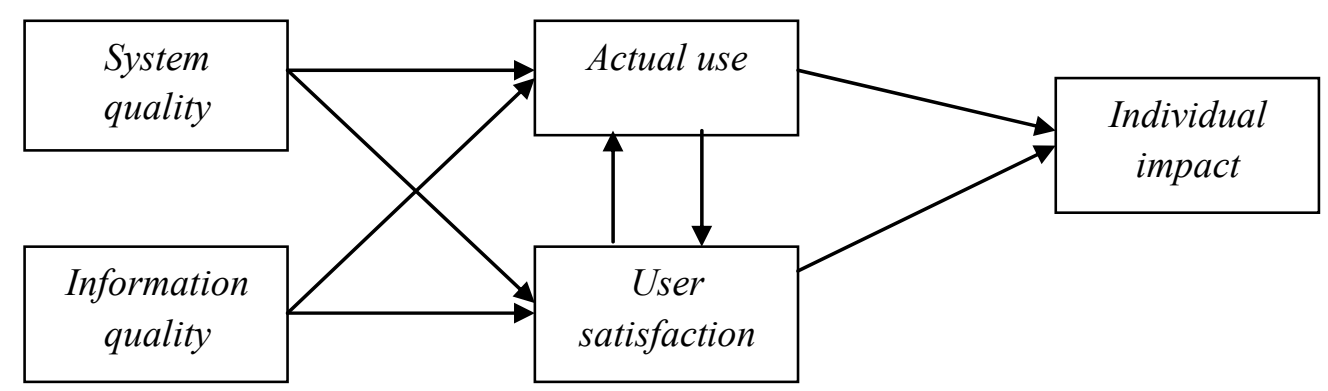

Figure 1. Iivari (2005) Research Model 
among others, are the intention to use and the actual use. Lassila and Brancheau (1999) identified the system usability as being based on the use or non-use of basic and advanced system capabilities. They eliminate the dimension of use when the system is mandatory. If this dimension is still used, then it does not affect the success of the system implementation. Meanwhile, the dimension of intention to use is normally used on voluntary and mandatory systems (Brown et al., 2002).

We selected the GM-AFIS of the Directorate of Finance, Gadjah Mada University as the research's subject. Accordingly, all hypotheses are stated in this context.

\section{System Quality, Information Quality, Service Quality and User Satisfaction}

The system quality is a factor that can affect users' satisfaction. If the quality of the implemented system is high, the system will improve the satisfaction of the system's users. Previous research has developed a measurement related to the system quality. Hamilton and Chervany (1981) used the data of proposed currency, response time, turnover time, data accuracy, reliability, completeness, system flexibility, and ease of use.

Many researchers have conducted examinations related to the system quality and users' satisfaction, one of them was Seddon and Kiew (1994). They found a consistency of positive relationships between the system's quality and users' satisfaction. Good system quality will result in an increase in the users' satisfaction. The system quality can be shown by its ease of use, user friendliness, interesting displays, ability to provide the information quickly, and in allowing the users to meet the information needs. Lin (2007) conducted a study on the use of online learning information systems. The results showed that the system quality had a positive influence on the users' satisfaction. We posit that a high quality information system leads to user satisfaction. Therefore, this study developed the following hypotheses.

H1: The system quality positively relates to the users' satisfaction.
The information quality is used to measure the quality of the information system output (Jogiyanto, 2007). The information is said to be qualified if the language is easy to understand and is universal, and can meet the users' needs so that they feel satisfied when using the information system. The information quality, according to DeLone and McLean (2003) includes the relevance and timeliness. They also explain that the system quality and users' satisfaction are positively related. A research conducted by Lin (2007) on on-line learning information systems also showed similar results with the research of DeLone and McLean (2003). According to Bailey and Pearson (1983), the measurement of information quality consists of its accuracy, precision, currency, timeliness, reliability, form, and relevance. We also posit that a high information quality leads to users' satisfaction. Therefore, this study formulates the following hypothesis.

$\mathrm{H} 2$ : The information quality is positively related to the users' satisfaction.

The service quality measures the aspect of supporting features that are provided by the division of the information system and information technology service personnel for the users (DeLone and McLean, 2003). The measures for the service quality are the completeness of the information that is provided by the system, personalization of content, and variations of the information. The service quality was originally used in the research of marketing discipline. It is measured from the buyers' point of view using a tool called SERVQUAL (Parasuraman, 1988). SERVQUAL consists of several dimensions, such as its reliability, responsiveness, assurance, empathy, and tangibility. Liu and Arnett (2000) stated that service quality is an important element of a Web site. DeLone and McLean (2003) found a positive effect of the service quality on the users' satisfaction. Other research by Khayun (2012), stated that the service quality of e-government in Thailand has a positive and significant effect on the users' satisfaction. Equivalent to $\mathrm{H} 1$ and $\mathrm{H} 2$, we formulate the following hypothesis. 
H3: The service quality is positively related to the users' satisfaction.

\section{Relationship of the Task-Technology Fit and Person-Job Fit with the Perceived Ease of Use}

The task-technology fit (TTF) involves 2 interacting components, namely the tasks to be performed and the technology used to help complete the task. When the capabilities of the technology match the users' task, the users feel that the system becomes easier to use in completing the task. Dihshaw and Strong (1999) suggested that the task-technology fit influenced the perceived ease of use. Klopping and McKinney (2004) suggested that the task-technology fit was positively related to the perceived ease of use. Because the users would not spend more effort, they get more in benefits from the system than the effort they put into it. In the other words, the users have highly cognitive fit. Therefore, this study formulates the following hypothesis.

H4a: The task-technology fit is positively related to the perceived ease of use.

The concept of the person-job fit is characterised by the suitability of the individuals' job for the capabilities they possess. Kristof-Brown et al. (2005) found that the person-job fit had a strong relationship with the work outcomes, such as job satisfaction. An employee with a low person-job fit will be less successful in completing their given job (Erdogan and Bauer, 2005) since a low person-job fit will affect the individuals' perception of the ease of the job at hand. Individuals' expertise in their job will not require them to spend additional efforts. Thus, this study formulates the following hypothesis.

H4b: The person-job fit is positively related to the perceived ease of use.

\section{Relationship between the Perceived Ease of Use and Users' Satisfaction}

The main indicator in measuring the success of the information system's implementation in an organization is the users' satisfaction. The users' satisfaction can be measured by several characteristics, such as the ease of and benefits from the use of the system, the information pre- sented, and how the system works (Al Gahtani, 2001). The perceived ease of use becomes the main focus because if a system is not easily understood by the users, it will have an impact on the users' satisfaction. Some researchers find a positive relationship between the perceived ease of use and users' satisfaction, such as Doll and Torkzadeh (1988), Seddon and Yip (1992), and Almarashdeh et al. (2005). Equivalent to the H4 reasoning, the users' will acquire additional benefits and reacquire these benefits more frequently. Then, they get satisfaction. Therefore, this study formulates the following hypothesis.

H5: The perceived ease of use is positively related to the users' satisfaction.

\section{Relationship between the Users' Satisfaction and Net Benefit}

The use of information systems does not only affect individual users' and groups' satisfactions, but also influences their individual users' and groups' performances. DeLone and McLean (2003) proposed a new dimension, i.e. the net benefit. The net benefit is the users' perception related to the individuals' net benefits of GM-AFIS. The users may feel satisfied if the system could provide them with benefits to complete their work, or vice versa. Iivari (2005) suggested that the users' satisfaction dominantly influences the individuals' use of the information systems. Another study showing the influence of the users' satisfaction to the net benefit is the research conducted by Khayun et al. (2012). Khayun et al. (2012) and Chong (2010) found a positive effect of the users' satisfaction on the net benefits. The users see their performance increase. Especially, they are able to do their job efficiently and effectively. Thus, this study formulates the following hypothesis.

H6: The users' satisfaction is positively related to the net benefit.

\section{Relationship between the Task-Technology Fit and Person-Job Fit against the Net Benefit}

Goodhue and Thompson (1995) found the dimension of the task-technology fit (TTF) in the use of information systems. The TTF becomes a significant factor to estimate the improvement in 
performance and effectiveness of the system's report users. Staples and Seddon (2004) found a strong correlation between the task-technology fit and performance. We posit that the users' performance improvement is one of the biggest benefits of the application of the system. They do their job with little expenditure of effort. Therefore, we formulate the following hypothesis.

\section{H7a: The task-technology fit is positively related to the net benefit.}

The person-job fit is an individuals' perception regarding how well an individuals' ability fits with the characteristics of the jobs they handle. For example, the workers may be asked whether their work is suited to their needs or preferences (Kristof, 1996). The person-job fit describes the extent to which the individuals feel that the technology they use will help them in completing the task. Several studies find that the person-job fit has an impact on performance (Caldwell and O'Reilly, 1990; Cable and Judge, 1996; Harris and Mossholder, 1994). All these studies indicated that the person-job fit had a positive impact on the net benefits, such as the increase in performance. We also posit that the users' performance improvement occurs because of their cognitive fit. It means that they have the capabilities and competencies to match the information systems requirements. Thus, we formulate the following hypothesis.

$\mathrm{H} 7 \mathrm{~b}$ : The person-job fit is positively related to the net benefit.

This research implicitly wants to show that the inducement of the task-technology fit into the DeLone and McLean model has a stronger relationship with the success of the application of GM-AFIS as compared to the inducement of the person-job fit. The citation is based on the assumption that the suitability of abilities, tasks handled, and the technological abilities of the users of the information systems will help the users in using the system. They will be assisted by, and have no difficulties, in using the system. Meanwhile, the suitability of the jobs with the expertise of the users does not guarantee that they are able to use the information systems if they are not support by posessing technological abilities. Accordingly, this study formulates the following hypothesis.

H8: The inducement of the task-technology fit has a stronger association than that of the person-job fit.

\section{RESEARCH METHOD}

\section{Subject}

The subjects of this study are the users of the GM-AFIS at the Directorate of Finance, Gadjah Mada University (GMU), Yogyakarta. In early 2013, the Directorate of Finance GMU started to enforce information system use onto the entire academic community. The information system is called the GM-AFIS, Gadjah Mada Accounting and Finance Information System. The application of the GM-AFIS is aimed at simplifying and shortening the process of prepaid expense proposals at 18 faculties and the university level. GM-AFIS is an integrated web-based system. The initial purpose of this system's development was to realize the transparency of the approval stage of account prepaid expense proposals. There are several reasons behind the implementation of the GM-AFIS at GMU, such as the increase in performance, the task complexity of GMU, the changes in the university's status, the level of security risk, and support for the "Go Green" policy.

This study chose the Directorate of Finance GMU as the research subject because it had developed the applications for the GM-AFIS. On the other hand, GMU is part of the public sector in education. Most research shows that the implementation of financial information systems is more successful in the private sector than in the public sector (Lhaksmi, 1991; Goldfinch, 2007). A similar phenomenon was also shown in research conducted by Thompson et al. (2009) and Khayun et al. (2012) who found that information systems applications in the public sector were not fully utilized.

\section{Data and Sample}

This study collected the data using survey techniques by distributing questionnaires. The 
population in this study contained all the users of the GM-AFIS. The study then conducted a purposive sampling technique with criteria, i.e. (1) users must have a GM-AFIS account, (2) users must have submitted a prepaid expense proposal and performed the approval process and been verified at least once since the system was implemented. We developed the questionnaire helped by the google drive application and sent it to the respondent's e-mail address. We also distributed questionnaires manually by visiting the respondents. In addition to providing the questionnaires, we also conducted direct observation of all the users of the GM-AFIS applications. We had to conduct these observations to ensure that the system actually was of good quality and the system had been established. Figure 2 and Figure 3 describe the research model investigated in this study.

\section{RESEARCH MODEL}

The measurement of the constructs of the system quality, information quality, service quality, users' satisfaction, and net benefits used a 4-item questionnaire which was adapted from DeLone and McLean (2003). The measurement of the task-technology fit constructs used a 10item questionnaire adapted from Goodhue (1995). Meanwhile, the measurement of the person-job fit construct used 5 questions adapted from Cable and DeRue (2002). The measurement of the perceived ease of use by employees had 5 questions adapted from Davis (1989). We measured all indicators using a Likert scale. This study considers that a Likert scale is the most appropriate technique for measuring a person's behavior where point 1 shows a strong disagreement answer and 5 for a strongly agree answer.

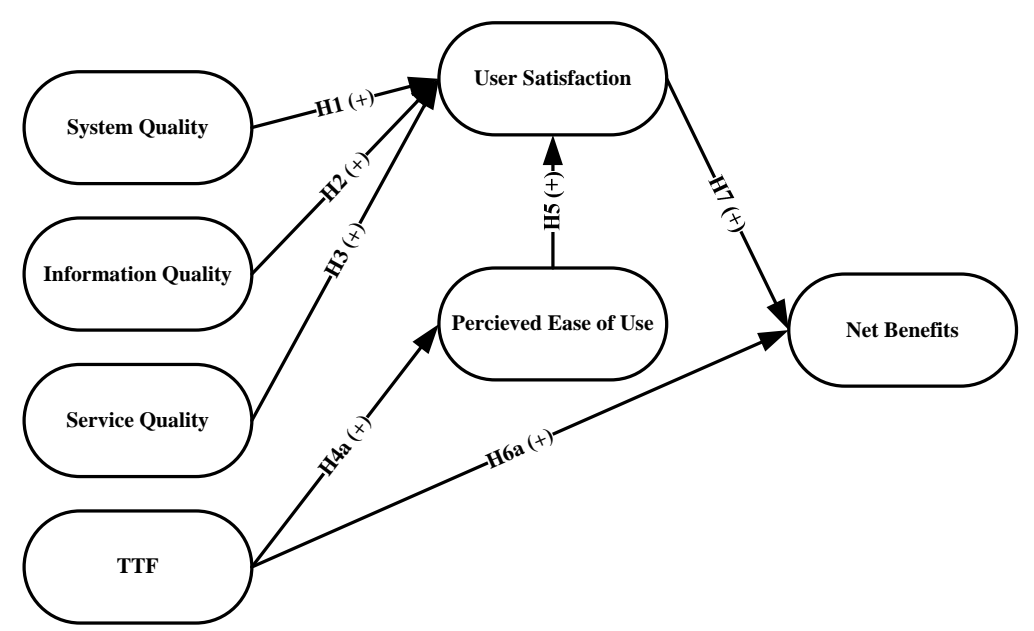

Figure 2. Research Model 1

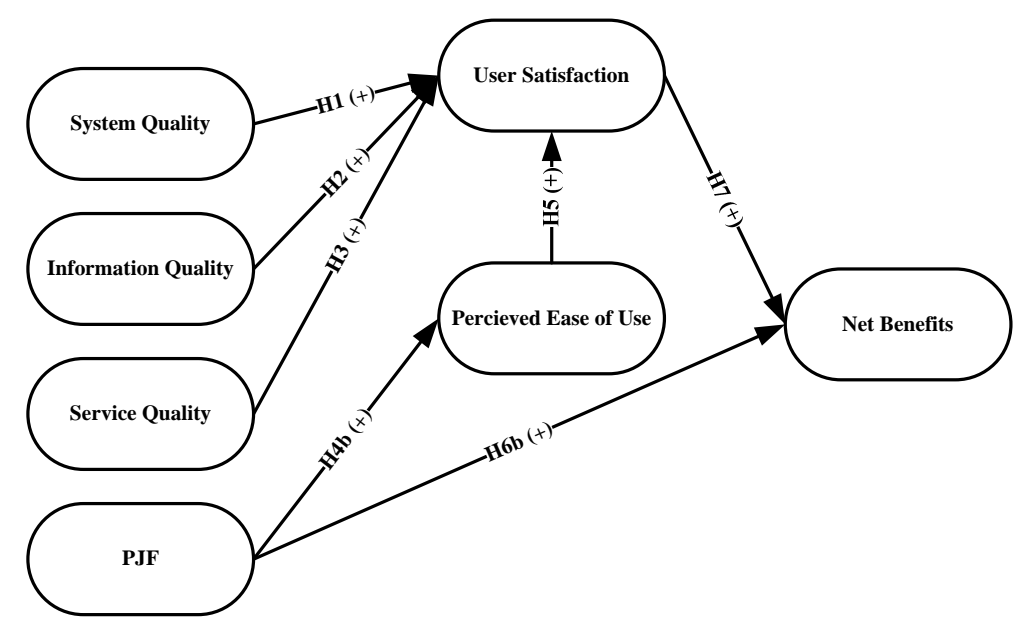

Figure 3. Research Model 2 
This study examined the validity and reliability along with the goodness of fit and our hypothesis. This study used structural equation modeling (SEM). We believe that SEM is the most appropriate tool to examine the relationships between complex variables, to examine the existence of unobservable or latent variables, and to test the model for goodness of fit (Gudono, 2012). The assessment of the goodness of fit processes the data whether they meet the assumptions required by the SEM or not. Whether a model is fit or not can be seen from the value of chi-square which has a significant probability, the value of the root mean square of approximation (RMSEA) which falls between 0.05 and 0.08 , the value of the goodness of fit index (GFI), and adjusted goodness of fit index (AGFI) which are greater than 0.90; the grades CMIN/DF which are smaller than 2.00, and the value of the Tucker Lewis index (TLI) which is greater than 0.95 (Hair, 2003).

\section{ANALYSIS, RESEARCH FINDINGS AND DISCUSSION}

\section{Descriptive Statistics}

This study uses data obtained from the results of the distributed questionnaires. The number of questionnaires distributed via e-mail was 175. Among those, 125 were returned. Meanwhile, the questionnaires that were directly distributed numbered 190, only 11 of which were not returned. Thus, the number of questionnaires which we used was 304 , or $96 \%$ of the total distributed questionnaires. We distributed and collected the research data between September $12^{\text {th }}$, 2013 and December $17^{\text {th }}, 2013$. Table 1 presents the demographics characteristics of the respondents as follows.

Table 1. The Demographics Characteristics of Respondents

\begin{tabular}{|c|c|c|c|c|}
\hline No & Item & Characteristics & Number & Percentage \\
\hline \multirow{3}{*}{1} & \multirow{2}{*}{ Gender } & Male & 132 & $43 \%$ \\
\hline & & Female & 172 & $57 \%$ \\
\hline & & Total & 304 & $100 \%$ \\
\hline \multirow{5}{*}{2} & \multirow{5}{*}{ Age } & $21-30$ & 74 & $24 \%$ \\
\hline & & $31-40$ & 138 & $45 \%$ \\
\hline & & $41-50$ & 82 & $27 \%$ \\
\hline & & $51-60$ & 10 & $3 \%$ \\
\hline & & Total & 304 & $100 \%$ \\
\hline \multirow{6}{*}{3} & \multirow{6}{*}{ Education } & High School & 23 & $8 \%$ \\
\hline & & Academy & 80 & $26 \%$ \\
\hline & & Undergraduate & 163 & $54 \%$ \\
\hline & & Post-Graduate & 29 & $10 \%$ \\
\hline & & Doctoral & 9 & $3 \%$ \\
\hline & & Total & 304 & $100 \%$ \\
\hline \multirow{3}{*}{4} & \multirow{2}{*}{ Major } & Accounting & 157 & $52 \%$ \\
\hline & & Non-Accounting & 147 & $48 \%$ \\
\hline & & Total & 304 & $100 \%$ \\
\hline \multirow{4}{*}{5} & \multirow{4}{*}{ Positions } & Submitter & 242 & $80 \%$ \\
\hline & & Approval Supervisor & 54 & $18 \%$ \\
\hline & & Verifier & 8 & $3 \%$ \\
\hline & & Total & 304 & $100 \%$ \\
\hline \multirow{4}{*}{6} & \multirow{3}{*}{$\begin{array}{c}\text { Frequency } \\
\text { of Use }\end{array}$} & 1-3 times & 61 & $20 \%$ \\
\hline & & 4-6 times & 71 & $23 \%$ \\
\hline & & $\geq 7$ times & 172 & $57 \%$ \\
\hline & & Total & 304 & $100 \%$ \\
\hline
\end{tabular}


We grouped the demographics characteristics of the respondents into 6 categories, i.e. gender, age, education level, background study (major in table 1), position, and frequency of using the GM-AFIS. Table 1 shows that the majority of respondents were female (57\%). Most respondents are at the undergraduate level (54\%). Therefore, based on their educational background, the majority of users have an undergraduate level accounting background. When viewed from the frequency of GM-AFIS use, most users have processed transactions more than 7 times daily since the system was implemented.

The descriptive statistics presented in Table 2 below is an overview of the respondents' answers to the items on the questionnaire. The table contains the values of minimum, maximum, mean, median, mode, and standard deviation of the respondents' answers.

Table 2 shows that the respondents' answers in each construct in this study produced good results. We can infer that the standard deviation values are smaller than the mean value. In addition, the data of all the respondents' perceptions distributes normally. This study also investigated the reliability and validity of each construct as described in the following section.

\section{The Results of Validity and Reliability Analysis}

This research determined the validity of the research instrument from its value resulting from the confirmatory factor analysis (CFA). A research instrument is valid if the value of the
CFA is greater than 0.50. Meanwhile, an instrument is reliable when its reliability value is greater than 0.70 (Hair et al., 1998). Overall, each construct met the lowest standard requirements. The construct of task-technology fit originally consisted of a 10-item questionnaire, but this study found that 5 questions were considered invalid. Items which had CFA values below 0.50 are excluded from our analysis. Furthermore, factor loading analysis for each indicator or item questioned met the minimum standard requirements of 0.70 (Hair et al., 1998). It means that all indicators have a good fit of validities. Table 3 shows the results of validity and reliability examinations for each construct.

\section{Analysis and Findings}

Figure 4 and Figure 5 summarize and present the results of the hypotheses examinations. The numbers in the figures are the $\beta$ coefficient. The results of hypotheses examination show that only 1 of the 8 hypotheses proposed in the research model 1 (TTF-DM) is not supported. The first hypothesis (H1) is statistically supported. This result supports previous research by Seddon and Kiew (1994), Lin (2007), and Iivari (2005). The second hypothesis (H2) is statistically supported. This result supports the findings of DeLone and McLean (2003) and Lin (2007). The third hypothesis (H3) is not supported. The service quality is not positively related to the users' satisfaction. It does not support the research by Khayun et al. (2012). The fourth hypothesis (H4A) is statistically supported. This result supports the research by Dihshaw and Strong (1999) and Klopping and McKinney

Table 2. The Descriptive Statistics of Respondents' Answers

\begin{tabular}{ccccccc}
\hline Constructs & Minimums & Maximums & Means & Medians & Modes & Std. Deviations \\
\hline KS & 1.00 & 5.00 & 3.535 & 4.00 & 4.00 & .790 \\
KI & 1.00 & 5.00 & 3.599 & 4.00 & 4.00 & .751 \\
KL & 1.00 & 5.00 & 3.040 & 3.00 & 3.00 & .898 \\
TTF & 1.00 & 5.00 & 3.610 & 4.00 & 4.00 & .787 \\
PJF & 2.00 & 5.00 & 3.720 & 4.00 & 4.00 & .736 \\
PEU & 1.00 & 5.00 & 3.674 & 4.00 & 4.00 & .776 \\
KP & 2.00 & 5.00 & 3.686 & 4.00 & 4.00 & .748 \\
NB & 2.00 & 5.00 & 4.034 & 4.00 & 4.00 & .638 \\
\hline
\end{tabular}

$\mathrm{N}: 304 ; \mathrm{KS}=$ System Quality, KI = Information Quality, KL = Service Quality, TTF=Task-Technology Fit, PJF $=$ Person-Job Fit, PEU = Perceived Ease of Use, KP = Users' Satisfaction, NB = Net Benefit 
Table 3. The Results of Validity and Reliability Examination

\begin{tabular}{|c|c|c|c|c|c|}
\hline Constructs & $\mathrm{N}$ of Items & Indicator & Factor Loading & CFA & $\begin{array}{l}\text { Construct } \\
\text { Reliability }\end{array}$ \\
\hline System Quality & 4 & $\begin{array}{l}\text { Flexibility } \\
\text { Turnaround } \\
\text { Recovery } \\
\text { Usability }\end{array}$ & $\begin{array}{l}0,589 \\
0,828 \\
0,644 \\
0,688\end{array}$ & 0.687 & 0.807 \\
\hline Information Quality & 4 & $\begin{array}{l}\text { Informativeness } \\
\text { Accessibility } \\
\text { Adaptability } \\
\text { Format }\end{array}$ & $\begin{array}{l}0,657 \\
0,736 \\
0,825 \\
0,680\end{array}$ & 0.724 & 0.875 \\
\hline Service Quality & 4 & $\begin{array}{l}\text { Visualization } \\
\text { Organization } \\
\text { Empathy } \\
\text { Service }\end{array}$ & $\begin{array}{l}0,527 \\
0,738 \\
0,841 \\
0,606\end{array}$ & 0.687 & 0.719 \\
\hline Task-Technology Fit & 5 & $\begin{array}{l}\text { Reliability } \\
\text { Availability } \\
\text { Up-to-date } \\
\text { Training } \\
\text { Time to Respond }\end{array}$ & $\begin{array}{l}0,632 \\
0,581 \\
0,575 \\
0,609 \\
0,571\end{array}$ & 0.594 & 0,715 \\
\hline Person-Job Fit & 5 & $\begin{array}{l}\text { Skill } \\
\text { Need-supplies fit } \\
\text { Demand-ability fit } \\
\text { Performance } \\
\text { Education Background }\end{array}$ & $\begin{array}{l}0,612 \\
0,801 \\
0,760 \\
0,605 \\
0,559\end{array}$ & 0.667 & 0.929 \\
\hline Perceived Ease of Use & 5 & $\begin{array}{l}\text { Ease of use } \\
\text { Informativeness } \\
\text { Clarity } \\
\text { Ease to learn } \\
\text { Complexity }\end{array}$ & $\begin{array}{l}0,778 \\
0,549 \\
0,819 \\
0,766 \\
0,735\end{array}$ & 0.729 & 0.865 \\
\hline User Satisfaction & 4 & $\begin{array}{l}\text { Performance } \\
\text { Experience } \\
\text { Decision } \\
\text { Helpful }\end{array}$ & $\begin{array}{l}0,882 \\
0,920 \\
0,704 \\
0,514\end{array}$ & 0.775 & 0.914 \\
\hline Net Benefit & 4 & $\begin{array}{l}\text { Timeliness } \\
\text { Valuable } \\
\text { Usefulness } \\
\text { Motivation }\end{array}$ & $\begin{array}{l}0,742 \\
0,773 \\
0,830 \\
0,814\end{array}$ & 0.790 & 0.963 \\
\hline
\end{tabular}

(2004). The fifth hypothesis (H5) is supported. This result is consistent with Seddon and Yip (1992). The sixth hypothesis (H6) is supported. This result is consistent with the previous study by Khayun et al. (2012). Lastly, the seventh hypothesis $(\mathrm{H} 7 \mathrm{a})$ is supported.

Meanwhile, the research model 2 (PJF-DM) shows that of the 8 hypotheses examined, 2 hypotheses are not supported. Hypothesis (H1) is statistically supported and this result corresponds with previous research by Seddon and Kiew
(1994), Lin (2007), and Iivari (2005). Hypothesis (H2) is statistically supported and so is in accordance with the research by DeLone and McLean (2003) and Lin (2007). Hypothesis (H3) is not statistically supported, and so it is conflict with a previous study by Khayun (2012). Hypothesis (H4b) is not statistically supported and so it is not in agreement with the previous study by Dihshaw and Strong (1999). Hypothesis (H5) is statistically supported and so in harmony with the result of the research by Staples and Seddon 
(2004). Hypothesis (H6) is statistically supported and concomitant with the research by Khayun et al. (2012). Lastly, hypothesis (H7b) is supported. This result is consistent with research by Staples and Seddon (2004). For more details, Table 4 shows the results of the hypothesis examinations of both research models.

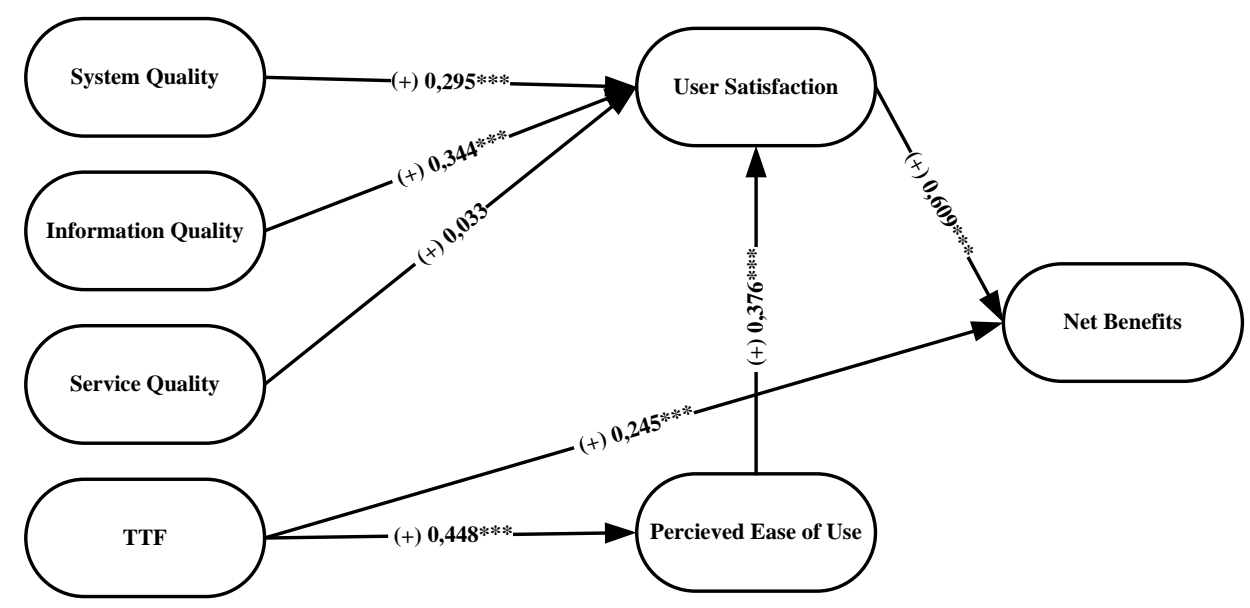

Figure 4. Hypotheses Examination of Research Model 1 (TTF-DM)

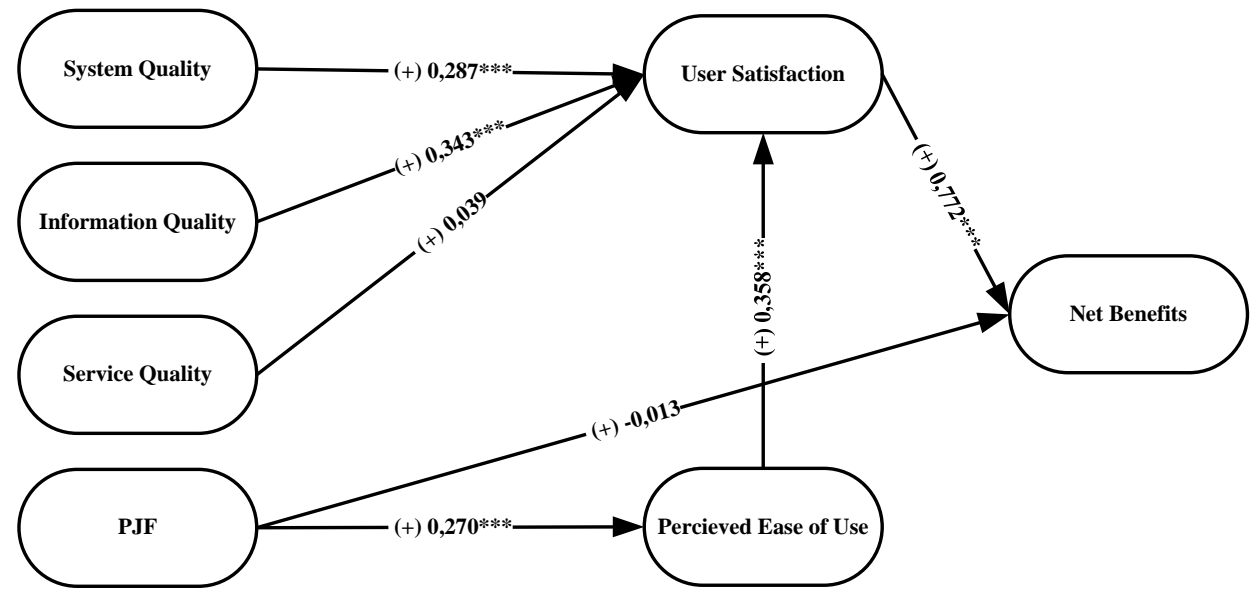

Figure 5. Hypotheses Examination of Research Model 1 (PJF-DM)

Table 4. The Results of hypotheses Examinations

\begin{tabular}{|c|c|c|c|c|c|}
\hline \multirow{2}{*}{$\begin{array}{l}\text { Hypo- } \\
\text { theses }\end{array}$} & \multirow[t]{2}{*}{ Causality Relationships } & \multicolumn{2}{|c|}{$\begin{array}{l}\text { Research Model } 1 \\
\text { (TTF-DM) }\end{array}$} & \multicolumn{2}{|c|}{$\begin{array}{l}\text { Research Model } 2 \\
\text { (PJF-DM) }\end{array}$} \\
\hline & & Coefficient & C.R $\mathrm{R}^{\#}$ & Coefficient & C.R $\#$ \\
\hline $\mathrm{H} 1(+)$ & System Quality $\rightarrow$ User Satisfaction & 0,295 & $4,399^{* * *}$ & 0,287 & $4,199^{* * *}$ \\
\hline $\mathrm{H} 2(+)$ & Information quality $\rightarrow$ User Satisfaction & 0,344 & $5,138^{* * *}$ & 0,343 & $5,144^{* * *}$ \\
\hline $\mathrm{H} 3(+)$ & Service Quality $\rightarrow$ User Satisfaction & 0,033 & 0,616 & 0,039 & 0,761 \\
\hline $\mathrm{H} 4 \mathrm{a}(+)$ & Task-Technology Fit $\rightarrow$ Perceived Ease of Use & 0,448 & $6,480^{* * *}$ & - & - \\
\hline $\mathrm{H} 4 \mathrm{~b}(+)$ & Person-Job Fit $\rightarrow$ Perceived Ease of Use & - & - & 0,270 & $3,767^{* * *}$ \\
\hline $\mathrm{H} 5(+)$ & Perceived Ease of Use $\rightarrow$ User Satisfaction & 0,376 & $6,122^{* * *}$ & 0,358 & $5,272^{* * *}$ \\
\hline H6 (+) & User Satisfaction $\rightarrow$ Net Benefit & 0,609 & $7,752^{* * *}$ & 0,772 & $10,188^{* * *}$ \\
\hline $\mathrm{H} 7 \mathrm{a}(+)$ & Task-Technology Fit $\rightarrow$ Net Benefit & 0,245 & $3,485^{* * *}$ & - & - \\
\hline $\mathrm{H} 7 \mathrm{~b}(+)$ & Person-Job Fit $\rightarrow$ Net Benefit & - & - & $-0,013$ & $-0,240$ \\
\hline
\end{tabular}

Note: *** significant at 0.01 level; ** at 0.05 level; * at 0.1 level. \# C.R used in the SEM is equivalent to $t$-value or calculated-t value in other software. 


\section{Goodness of Fit Test of the Research Model}

All of the results are mostly consistent with the research by Staples and Seddon (2004); therefore the eighth hypothesis (H8) is supported. This study finds that more hypotheses of the research model 1 are supported than that of the research model 2. Our test provides the results of the goodness of fit test of the model as follows. The results of the goodness of fit test of the research model 1 and 2 show that both models are fit. Most of the criteria are met. Table 5 presents the results of the goodness of fit test of the research models.

Table 4 shows that the chi-square value of the research model 1 is greater than that of model 2. The probability of both models show significant values. The significant values of chisquare are expected in this study. The values of the CMIN/DF in both models show good results. The value of CMIN/DF in both models is less than 2.00. The value of CMIN/DF in the research model 1 is less than that of research model 2. The values of RMSEA, GFI, AGFI, and CFI in both models also meet the criteria. Both models are free from endogeneity problems, because their errors do not correlate with their independent variables, as shown by the low value of CMIN/DF and RMSEA compared with their standards. The values of RMSEA, GFI, AGFI, and CFI in the research model 1 are greater than that of research model 2 .

\section{Implications}

Practically, the GM-AFIS has adequate quality. It provides the menus to access the data needed. The system has a dashboard that contains the module to process the prepaid expense proposals. In addition, its information quality is also adequate. One of the criteria for assessing the system quality is its time saving. The GMAFIS is able to provide the time efficiency and information currency to its users. This evidence is laid down in the approval log provided by the system. This approval $\log$ is a history or track record that displays the process of prepaid expense proposals. Thus, the users can monitor the progress of their prepaid expenses, they are either still being processed or have been processed. In the event of a revision to the prepaid expenses proposal at the approval supervisor or verifier level, they can immediately find out and revise it.

The service quality of the GM-AFIS has not been able to give satisfaction to the users. Sometimes, the proposals for prepaid expenses are not immediately processed. The users still have to notify the competent authorities manually when there is a new prepaid expenses proposal. In addition, the system does not provide FAQ (Frequently Asked Questions) and an on-line chat system. This condition forces the users to use other media if they want to communicate with the administrators when they encounter problems regarding the system. The user is forced to contact the administrator by phone, memo, or e-mail. These conditions make the users waste time when experience difficulties with the system. Hence the system does not provide an adequate service quality to its users.

The suitability of the work handled by each GMU employee with the ability to use the GMAFIS has not yet been able to provide any benefits for the individuals and organizations. Factually, the application of the system is still far

Table 5. The Results of the Goodness of Fit Test of the Research Models

\begin{tabular}{cccc}
\hline Goodness of Fit & Cut-off Standards & Model 1 (TTF-DM) & Model 2 (PJF-DM) \\
\hline Chi-Square & Small & 659.739 & 692.822 \\
$P$ & $\geq 0.05$ & 0.000 & 0.000 \\
CMIN/DF & $\leq 2.00$ & 1.718 & 1.818 \\
RMSEA & $\leq 0.08$ & 0.049 & 0.052 \\
GFI & $\geq 0.90$ & 0.880 & 0.875 \\
AGFI & $\geq 0.90$ & 0.885 & 0.847 \\
TLI & $\geq 0.95$ & 0.922 & 0.914 \\
CFI & $\geq 0.95$ & 0.931 & 0.924 \\
\hline
\end{tabular}


from ideal. It is more applicable due to its mandatory use, but the users do not feel the benefits of the system. Additionally, they are more inclined to use the system just to meet their obligations and the procedural requirements in the process of prepaid expense proposals for their operational activities. In addition, the necessary training in the system use is still less than adequate. Training was only conducted when the system was about to be applied. The training is also considered as less than adequate as the educational background and skills of the users are different so that their comprehension of the system also differs.

On the other hand, the users have to run the system manually for submission of prepaid expense proposals. Their performance does not meet optimal levels because they have to submit the prepaid expense proposals twice, manually and by computer. This, of course, increases the users' workload and therefore the application of the GM-AFIS is not efficient. From the organizational point of view, every functional department must still have a budget issued for papers and take an even longer time just to process the submission of prepaid expense proposals. The principle of the system was to reduce the time taken for the processing of prepaid expense proposals. In addition, the system has some disadvantages because it requires the users to continue the process despite the fact that they are on their way out. There are many approval supervisors and verifiers who do not posses the required tools to complete this process.

In our study, the results from the research model 1 (TTF-DM) are better than those of research model 2 (PJF-DM). Research model 1 (TTF-DM) provides a better explanation of the success of mandatory information systems. The suitability of tasks, expertise, and technology determine the success of the GM-AFIS application. The users who have the high task-technology fit will find it easier to operate the system. They have no doubts about using the technology because the tacit knowledge within the users has been formed. It can be seen from the educational background of the users between S1 up to S3. In addition, the users who have the task-technology fit are less likely to face obstacles in operating the mandatory system. The mandatory information system insists that the users operate the system. Thus, the users are considered to be free from all obstacles in using the technology.

This study has some findings which are expected to contribute to all related parties. The findings imply that policy makers should take changes in the practical conditions into considerations. When the facts on the ground indicate inefficient use of the system, a new policy enforcing a full on-line process of prepaid expense proposals should be put in place. Manual activities should be performed only when printing a statement or bank transaction receipt. Consequently, a good quality system, like the application of the GM-AFIS, does not always run smoothly in its implementation. Before the system is implemented, the readiness of the related parties must be ensured. We documented that, in this case, the prepaid expense proposal, it is not a "stand alone" system (but requires both manual as well as computerized submissions).

The implication for senior management is that their roles are very critical to the success of the implementation of new information systems. The top managers should be focused on the service improvements required and increasing the users' knowledge since most of the obstacles are not in terms of the technological capabilities. They need to get more acquainted with the use of the GM-AFIS. The number of system users is reaching 1000 and there are different levels of understanding of the system. Many users experience technical faults when using the system. Training, which should have been provided before implementing the system, is still not adequate. Thus, the human resources department needs to provide more periodic training sessions and reviews regarding the use of this system. Senior management should also monitor the total number of GM-AFIS user's accounts. We observed that there are users who have more than 1 account. Too many users' accounts in the system will make it more difficult for management to monitor and control. 
For the system designers, an on-line communication system between the administrator and the user, such as FAQs and/or on-line chat, is a necessity. An on-line communication facility is needed to connect the users to assistance when they experience problems using the system, so they can get the help they need without having to wait long periods to get answers to the problems they face. In addition, the system designers should consider a more user friendly system. The users are often confused by the sub-menus in the system, such as tax calculation or journal entries. The system designers have the responsibility to conduct socialization and training for all users. The training should focus on the suitability between the users' tasks and their capabilities. The facts show that the problems which arise in the system implementation are rarely caused by a mismatch between the users' tasks and their knowledge.

The users should get more acquainted with the GM-AFIS. They must ascertain their readiness before using the system. Any parts of the system that they do not understand should be dealt with speedily. This can be achieved by forming on-line groups or forums to inform and share knowledge. In addition, top management should retire any incapable users.

\section{CONCLUSION}

This study compares the inducement of the task-technology fit with the person-job fit in the model of information system success. The results show that, from the research model 1 , only 1 hypothesis is not supported. That hypothesis relates the service quality to the users' satisfaction. Meanwhile, in research model 2, 2 hypotheses are not supported. These hypotheses are the relationship of the service quality to the users' satisfaction and the relationship of the person-job fit to the net benefit. It means that the task technology fit has a stronger association with the success of information system implementation than the person job fit model.

There are reasons to explain this comparison result. It signifies that the current users already possess the required ability and agility to use the new technology. But, the users still need to ad- just their capabilities and competencies to the characteristics of the technology, once this is done it would make the individuals' performance more effective and efficient. It means that the user should not require extra cognitive efforts to use this GM-AFIS. We support the cognitive fit theory. On the other hand, the person-job fit is considered insufficient to ascertain the success of the information system implementation. This is because, in addition to the suitability of the individuals' characteristics for the job they handle, they too must adjust their capabilities and competencies with the characteristics of the technology in order to gain the most benefit from the information system implementation.

This study suggests that the inducement of person job fit is low-to-moderately supported. We argue that most users' educational background is somehow irrelevant to their jobs. It has implications for the job qualifications and recruitment policies. The Gadjah Mada human resources department should consider the users' capabilities and competencies in conformity with their job qualification. For the recruitment policies, the non-accounting and finance staff would be better replaced by those with the right expertise. It means that the GM-AFIS should be supported by human resources whose specialized capabilities and competencies are in accounting and finance.

This study has several limitations. Firstly, the researchers have no control over the respondents who answered the questionnaires. Thus, this study has a bias in the administrated questionnaires and delivery of the subjective judgments regarding the use the GM-AFIS. However, the researchers tried to anticipate this condition by directly observing the system application in use. Secondly, the researchers found some difficulties in researching the respondents. This occured because some users have the same data and there were difficulties in meeting the users at the level of approval supervisors and verifiers. Thirdly, the limitations of this study possibly appear in the reasons for the justification of hypothesis H8. The researchers only relied on the statistical figures in the results of 
each parametric hypothesis examination to compare both models. Fourthly, the researchers did not use a specific test to obtain a stronger research model to illustrate the application of a mandatory information system. Lastly, the number of questions in this survey is relatively small in comparison with the large number of respondents. This will affect the results of the data normality test.

Further study should be aimed at examining the modified DeLone and McLean model by inducing the person-environment fit. This fit theory consists of 3 concepts, namely, the tasktechnology fit, person-job fit, and personenvironment fit. Researchers can further compare these 3 concepts of fit theory to determine the best inducement to describe the success of the implementation of the mandatory information systems. The person-environment fit is the balance relationship between the individual and the environment. The person-environment fit focuses on the work pressure faced by each individual in completing their work. Further research can use the measure of person-environment fit adopted from Cooper et al. (2001).

\section{REFERENCES}

Al-Gahtani, S., 2001. The applicability of TAM outside North America: An empirical test in the United Kingdom. Information Resources Management Journal, 14(3), pp. 37-46.

Almarashdeh, I.A., Sahari, N., Zin, N.A.M., dan Almazdi. M., 2005. The Success of Learning Management System among Distance Leaners in Malaysian Universities. Journal of Theoritical and Applied Information Technology, 21(2), pp. 80-91.

Bailey, James E. \& Sammy W, Pearson, 1983. Development of A Tool for Measuring and Analysis Computer User Satisfaction. Management Science, 29(5), pp. 530-545.

Brown S.A., A.P. Massey, M.M. MontoyaWeiss, and J.R. Burkman, 2002. "Do I really have to? User Acceptance of Mandatory Technology." European Journal of Information Systems, 11, pp. 283-295.

Cable, D.M., and Judge, T.A., 1996. PersonOrganization Fit, Job Choice Decisions, and Organizational Entry, Organizational Beha- vior and Human Decision Processes, 67, pp. 294-311.

Cable, D.M., and DeRue, D.S., 2002, 'The Convergent and Discriminant Validity of Subjective Fit Perceptions,' Journal of Applied Psychology, 87, pp. 875-884.

Carless, S.A., 2005. Person-Job Fit versus Person-Organization Fit as Predictors of Organizational Attraction and Job Acceptance Intentions: A Longitudinal Study, Journal of Occupational and Organizational Psychology, 78, pp. 411-429.

Caldwell, David F., and O'Reilly, Charles A., III., 1990. Measuring Person-Job Fit with a Profile-Comparison Process. Journal of Applied Psychology, Vol. 75, Iss. 6; p. 648.

Chong, H., Cates, D., and Rauniar, R., 2010. Validity of DeLone and McLean's E-Commerce Model in B2C Students Loan Industry. Journal of International Technology and Information Management, 19(1), pp. 75-95.

Cooper, C. L., Liukkonen, P., and Cartwright, S., 1996. Stress Prevention in the Workplace: Assessing the Costs and Benefits to Organizations, Luxembourg: Office for Official Publications of the European Communities.

Davis, F.D., 1989. Perceived Usefulness, Perceived Ease of Use, and User Acceptance of Information Technology. MIS Quarterly, 13(3), pp. 319-340.

Dehning, B., V. J. Richardson, and R. W. Zmud, 2003. The Value Relevance of Announcements of Transformational Informational Technology Investments. MIS Quarterly, 27(1), pp. 637-656.

DeLone, William H., and Ephraim R. McLean, 1992. Information systems success: The quest for the dependent variable. Information Aviv/comm. Research, 3(1), pp. 60-95.

2003. The DeLone and McLean Model of Information Systems Success: A TenYear Update. Journal of Management Information Systems, 19(4), pp. 9-30.

2004. Measuring e-Commerce Success: Applying the DeLone \& McLean Information Systems Success Model. International Journal of Electronic Commerce, 9(1), pp. 31-47. 
Dishaw, M.T. and Strong, D.M., 1999. Extending the Technology Acceptance Model with Task-Technology Fit Constructs. Information and Management, 36(1), pp. 9-21.

Doll, W.J. and Torkzadeh, G., 1988. The Measurement of End-User Computing Satisfaction. MIS Quarterly, 12(2), pp. 259-274.

Erdogan, B., and Bauer, T.N., 2005. Enhancing Career Benefits of Employee Proactive Personality: The Role of Fit with Jobs and Organizations, Personnel Psychology, 58, pp. 859-891.

Edwards, Jeffrey R., 1991, Person-Job Fit: A Conceptual Integration, Literature Review, and Methodological Critique, International Review of Industrial and Organizational Psychology, Vol.: 6, Cary L. Cooper, and Ivan T. Robertson, eds., Chichester, UK: Wiley, pp. 283-357.

Gentner, D., and Stevens, A. L., 1983. Mental Models, Hillsdale, NJ: Lawrence Erlbaum and Associates.

Goldfinch, Shaun, 2007. Pessimism, Computer Failure, and Information Systems Development in the Public Sector. Public Administration Review; ProQuest, p. 917.

Goodhue, D.L and Thompson, R.L., 1995. TaskTechnology Fit and Individual Performance. MIS Quarterly, 19(2), pp. 213-236.

Grover, G., Jeong, S.R., and Segars, A.H., 1996. Information systems effectiveness: The construct space and patterns of application. Information \& Management, 31(4), pp. 177191.

Gudono, Gudono, 2012. Multivariate Data Analysis. Yogyakarta: BPFE Printing, Co. Ltd., pp. 242-254.

Hair, J., Blake, W., Babin, B., and Tatham, R., 2006. Multivariate Data Analysis. Prentice Hall, New Jersey.

Hamilton, S. and Chervany, N.L., 1981. Evaluating Information Systems Effectiveness Part 1: Comparing Evaluation Approaches. MIS Quarterly, 5 (4), December, pp. 55-69.

Harris, Stanley G, Mossholder, Kevin W, Oswald, Sharon L., 1994. Vision salience and strategic involvement: Implications for psychological attachment to organization and job. Strategic Management Journal, 15(6), pp. 477-490.
Iivari, J., 1997. User Information Satisfactions: A Critical Review. Encyclopedia of Library and Information Science, 60(Supplement 23), pp. 341-346.

2005. An empirical test of the DeLone-McLean model of information system success. ACM SIGMIS Database, 36(1), pp. 8-27.

Jogiyanto, H.M., 2007. Behavioral Information Systems. Yogyakarta: Andi Offset, Co. Ltd.

Kamis, A., Kaufaris, M., and Stern, T., 2008. Using An Attribute-Based Decision Support System for User-Customized Products Online: An Experimental Investigation. MIS Quarterly, 32 (1), pp. 159-177.

Khayun, Vachiraporn, Peter Ractham, and Daniel Firpo, 2012. Assessing e-EXCISE Success with DeLone and McLean's Model. Journal of Computer Information Systems, pp. 31-40.

Klooping, Inge M., and McKinney, Earl, 2004. Extending the Technology Acceptance Model and the Task-Technology Fit Model to Consumer E-Commerce. Information Technology, Learning, and Performance Journal, 22(1), pp. 35-48.

Kristof-Brown, A.L., 1996. 'Person-Organization Fit: An Integrative Review of its Conceptualizations, Measurement, and Implications,' Personnel Psychology, 49, pp. 1-49.

Kristof-Brown, A.L., Zimmerman, R.D., and Johnson, E.C., 2005. 'Consequences of Individuals' Fit at Work: A Meta Analysis of Person-Job, Person-Organization, PersonGroup, and Person-Supervisor Fit,' Personnel Psychology, 58, pp. 281-342.

Lassila, K.S., and Brancheau. J.C., 1999. Adoption and utilization of commercial software packages: Exploring utilization equilibrium, transitions, triggers, and tracks. Journal of Management Information Systems, 16(2), pp. 63-90.

Lin, Hsiu-fen, 2007. Measuring Online Learning System Success: Applying The Update DeLone and McLean Model. Cyber Psychology \& Behavior, 10(4), pp. 807-820.

Liu, C., and Arnett, K., 2000. Exploring the factors associated with Web site success in the context of electronic commerce. Information \& Management, 38(4), pp. 23-33. 
Mason, R.O., 1978. Measuring information output: A communication systems approach. Information and Management, pp. 219-234.

Mohan, Lakshmi, William K. Holstein, and Robert B. Adams, 1990. EIS: It Can Work in the Public Sector. MIS Quarterly, pp. 435-448.

Parasuraman, A., Valarie, A.Z and Leonard, L.B., 1988. SERVQUAL: A Multiple-Item Scale for Measuring Consumer Perception of Service Quality. Journal of Retailing, 64(1), Spring, pp. 12-40.

Petter, Stacie, William DeLone, and Ephraim McLean, 2008. Measuring Information Systems Success: Models, Dimensions, Measures, and Interrelationships. European Journal of Information Systems, 17, pp. 236-263.

Seddon, Peter B. and Yip S-K., 1992. An empirical evaluation of user information satisfaction (UIS) measures for use with general ledger accounting software. Journal of Information Systems, 6(1), pp. 75-98.

Seddon, Peter B., 1997. A Respecification and Extension of DeLone and Mclean Model of IS Success. Information System Research, 8(3), pp. 240-253.
Shannon, C.E., and Weaver, W., 1949. The Mathematical Theory of Communication. Urbana: University of Illinois Press.

Sumiyana, Zaki Baridwan, Slamet Sugiri, dan Jogiyanto Hartono M., 2010. Accounting Fundamentals and the Variation of Stock Price: Factoring in the Investment Scalability. Gadjah Mada International Journal of Business, 12(2), pp. 189-229.

Staples, D.S., and Seddon, P.B. 2004. Testing The Technology to Performance Change Model. Journal of Organizational and End User Computing, 16(4), pp. 17-36.

Thompson, R.L., Higgins, C.A., and Howell, J.M., 1995. "Personal Computing Toward a Conceptual Model of Utilization," MIS Quarterly, 15(1), pp. 125-143.

Theo, Thompson S.H., Shirish C. Srivastana, and Li Jiang, 2008. Trust and Electronic Government Success: An Empirical Study. Journal of Management Information Systems, 25(3), pp. 99-131.

Vessey, I., 1991. "Cognitive Fit: A TheoryBased Analysis of the Graphs Versus Tables Literature.” Decision Sciences, 22(2), pp. 219-240.

Zuboff, S., 1988. In the Age of the Smart Machine: The Future of Work and Power. NY: Basic Books, New York. 